\title{
A STUDY OF RELATION BETWEEN SYMPTOMS AND FEV1 (FORCED EXPIRATORY VOLUME IN ONE SECOND) IN PATIENTS WITH COPD AND BRONCHIAL ASTHMA
}

\author{
Damaraju Seshagirirao', Juvvala Kishan Srikanth ${ }^{2}$
}

1 Professor, Department of Pulmonology Medicine, Guntur Medical College, Guntur.

2 Postgraduate Student, Department of Pulmonology Medicine, Guntur Medical College, Guntur.

\section{ABSTRACT}

\section{BACKGROUND}

To study the background, clinical manifestations and relation between clinical symptoms and FEV1 (Forced Expiratory Volume in one second) in patients with chronic obstructive pulmonary disease and bronchial asthma. Clinical symptoms are in direct relation with COPD severity, but no relation with bronchial asthma in our study.

\section{MATERIALS AND METHODS}

Study Design- This is a hospital-based, cross-sectional study of patients with COPD and Bronchial asthma as defined by GOLD in 2015 and GINA in 2015; 47 patients with a diagnosis of COPD and 47 patients of Bronchial asthma attending the outpatient department or admitted in the medical wards/ICU of Government Fever Hospital/Guntur Medical College were examined and data were collected on a pretested proforma. A detailed history was taken and a thorough clinical examination was done in all patients. Five symptoms (cough, dyspnoea, wheeze, tightness of chest, nocturnal symptoms) were recorded on a two-point scale. Zero point was given for absence of symptom and one point for presence of symptom. A cumulative symptom score was calculated with a maximum score of five. Dyspnoea was also graded according to Modified Medical Research Council (MMRC) grading of dyspnoea. $\mathrm{FEV}_{1}$ was measured by spiroanalyser (Vitalograph), meeting the standard criteria. Spirometry was obtained with the patient seated and wearing nose clips. The best of three reproducible measurements was taken for analysis. The post-bronchodilator FEV 1 was assessed at 20 minutes after the inhalation of $200 \mu \mathrm{g}$ of salbutamol using a metered-dose inhaler with a spacer device. The descriptive statistics was done to describe FEV1 and other data symptoms in both COPD and Bronchial asthma patients. The data was analysed using Excel and SPSS version 20. The results were expressed in terms of percentage, means and standard deviation, and relevant tests of significance like Independent sample " $\mathrm{t}$ " test were applied and $\mathrm{p}<0.05$ was considered as statistically significant.

\section{RESULTS}

The procedure workup consists of clinical history along with chest x-ray and spirometry. If both of them satisfied the inclusion and exclusion criteria, then routine investigations like blood investigations and spirometry results were compared for Asthma and Chronic obstructive pulmonary disease.

\section{CONCLUSION}

Our study emphasises the importance of using objective assessment of lung function in both Bronchial asthma and COPD patients prior to implementation of medical treatment strategies. There is a statistically significant difference between COPD and Bronchial Asthma for FEV1 pre, FEV1 post and Total Score $(\mathrm{p}<0.05)$.

\section{KEYWORDS}

Bronchial Asthma, COPD, Clinical Symptoms, Chest X-Ray, Spirometric Values.

HOW TO CITE THIS ARTICLE: Seshagirirao D, Srikanth JK. A study of relation between symptoms and FEV1 (forced expiratory volume in one second) in patients with COPD and bronchial asthma. J. Evolution Med. Dent. Sci. 2017;6(47):3651-3655, DOI: $10.14260 /$ Jemds/2017/787

\section{BACKGROUND}

This is a hospital-based, cross-sectional study of patients with COPD and bronchial asthma as defined by GOLD in 2015 and GINA in 2015. Gold defined COPD as a common, preventable and treatable disease characterised by persistent airflow limitation that is usually progressive and associated with enhanced chronic inflammatory response in the airways and lungs to the noxious particles or gases. Exacerbations and comorbidities contribute to the overall severity in individual

Financial or Other, Competing Interest: None.

Submission 15-03-2017, Peer Review 01-06-2017,

Acceptance 06-06-2017, Published 12-06-2017.

Corresponding Author:

Dr. Damaraju Seshagirirao,

\#1-9-23, Sriramnagar, Kakinada.

E-mail: drdsraosai@gmail.com

DOI: $10.14260 /$ jemds/2017/787 patients.(1) 47 patients with a diagnosis of COPD and 47 patients of Bronchial asthma attending the outpatient department or admitted in the medical wards/ICU of Government Fever Hospital/Guntur Medical College were examined and data collected on a pretested proforma. COPD and bronchial asthma both were diagnosed based on clinical criteria and spirometry. (2)

A detailed history was taken and a thorough clinical examination was done in all patients. Five symptoms (cough, dyspnoea, wheeze, tightness of chest, nocturnal symptoms) were recorded on a two point scale. Zero point was given for absence of symptom and one point for presence of symptom. There is a variable relationship between clinical parameters and pulmonary functions.(3) The most commonly used way to express disease severity is by assessing the $\mathrm{FEV}_{1}$ as a measure for airway obstruction.(4) A cumulative symptom score was calculated with a maximum score of five. Dyspnoea 
was also graded according to Modified Medical Research Council (MMRC) grading of dyspnoea. $\mathrm{FEV}_{1}$ was measured by spiroanalyser (Vitalograph), meeting the standard criteria. Spirometry was obtained with the patient seated and wearing nose clips. The best of three reproducible measurements was taken for analysis. The post-bronchodilator $\mathrm{FEV}_{1}$ was assessed at 20 minutes after the inhalation of $200 \mu \mathrm{g}$ salbutamol using a metered-dose inhaler with a spacer device.

\section{Aims}

To study the background, clinical manifestations and relation between clinical symptoms and FEV1 (Forced Expiratory Volume in one second) in patients with chronic obstructive pulmonary disease and bronchial asthma.

\section{Inclusion Criteria}

Patients of either gender suffering from chronic obstructive pulmonary disease or bronchial asthma.

\section{Exclusion Criteria}

Patients with other causes of airflow obstruction like tumour, foreign bodies, laryngospasm and cardiogenic pulmonary oedema.

\section{MATERIALS AND METHODS}

- Clinical examination and case sheet.

- Symptomatology.

- Dyspnoea scale.

- $\quad$ Chest x-ray.

- Spirometry values, pre- and post-bronchodilator comparison.

- The data was analysed using Excel and SPSS version 20 . Results were expressed in terms of percentage, means and standard deviation, and relevant tests of significance like independent sample " $\mathrm{t}$ " test were applied and $\mathrm{p}<$ 0.05 was considered as statistically significant.

94 patients, 47 bronchial asthma and 47 COPD patients are examined thoroughly. Symptoms are tabulated. Main five cardinal symptoms are cough, sputum production, dyspnoea, chest tightness and nocturnal wheeze. Patients are tested spirometrically and result of FEV1 is compared. A postbronchodilator spirometric values are also tabulated. This is a prospective study done in Guntur Medical College between 2015 and 2016. In this study, 94 patients were studied; 47 patients were asthmatics and 47 were COPD patients. Of 47 asthmatics, males are 27 and females are 20. In total COPD patients, 21 are males and 6 are females in our study.

\section{RESULTS}

\begin{tabular}{|c|c|c|c|}
\hline Characteristics & & Number & \\
\hline & & & \\
\hline Age (18 - 71 years) & & 47 & \\
\hline Average (33.3 \pm 14.1$)$ & & & \\
\cline { 4 - 4 } & & & \\
\hline Sex & & & \\
\hline Male (19 - 71 years) & & $27(57 \%)$ & \\
\hline Female (18 - 55 years) & & $20(43 \%)$ & \\
\hline Smoking & & & \\
\hline Current & & $13(28 \%)$ & \\
\hline
\end{tabular}

\begin{tabular}{|c|c|c|c|}
\hline Ex. Smoker & & $7(15 \%)$ & \\
\hline Never & & $27(57 \%)$ & \\
\hline Symptoms & & & \\
\hline Cough & & $27(57.5 \%)$ & \\
\hline Wheeze & & $27(57.5 \%)$ & \\
\hline Dyspnoea & $24(51.1 \%)$ & \\
\hline Tightness of Chest & $28(59.6 \%)$ & \\
\hline Nocturnal Symptoms & $26(55.3 \%)$ & \\
\hline \multicolumn{2}{|c|}{ Table 1. Patient Characteristics in Bronchial Asthma } \\
\hline
\end{tabular}

In Bronchial Asthma, average age of patients is $33.3 \pm$ 14.1. Males are 27 (57\%) and females are 20 (43\%). Symptoms are Cough 27 (57.5\%), Wheeze 27 (57.5\%), Dyspnoea 24 (51.1\%), Tightness of chest 28 (59.6) and Nocturnal symptoms 26 (55.3\%).

\begin{tabular}{|c|c|}
\hline $\begin{array}{c}\text { MMRC Grade } \\
\text { of Dyspnoea }\end{array}$ & $\begin{array}{c}\text { Average FEV } \\
\text { Volume in Litre }\end{array}$ \\
\hline 0 & 2.24 \\
\hline I & 2.12 \\
\hline II & 1.86 \\
\hline III & 1.74 \\
\hline IV & No patients in this category \\
\hline $\begin{array}{c}\text { Table 2. Grading of Bronchial Asthma Patients } \\
\text { depending on MMRC Grade and Average FEV } \text { I }_{\mathbf{1}}\end{array}$ \\
\hline
\end{tabular}

An average $\mathrm{FEV}_{1}$ volume in litre in MMRC grade of dyspnoea 0 , I, II, III are 2.24, 2.12, 1.86, 1.74 respectively. No patients in MMRC grade of dyspnoea IV category.

\begin{tabular}{|c|c|}
\hline FEV $_{\mathbf{1}}$ Test & Average Value in Litre \\
\hline FEV $_{1}$ pre-bronchodilator & $1.97 \pm 0.82$ \\
\hline FEV $_{1}$ post-bronchodilator & $2.54 \pm 0.86$ \\
\hline \multicolumn{2}{|c|}{ Table 3. Study of Spirometry in Bronchial Asthma } \\
\hline
\end{tabular}

An FEV 1 pre-bronchodilator Spirometry in Bronchial Asthma is $1.97 \pm 0.82$ litre and $\mathrm{FEV}_{1}$ post-bronchodilator is $2.54 \pm 0.86$ litre.

In Bronchial asthma patients, major symptoms are chest tightness 28 (59.6\%) and Cough and Wheeze 27 (57.5\%).

\begin{tabular}{|c|c|c|}
\hline \multicolumn{2}{|c|}{ Characteristics } & \multirow[t]{2}{*}{ Number } \\
\hline \multirow{3}{*}{ Age } & & \\
\hline & (54 - 78 years) & \multirow{2}{*}{47} \\
\hline & Average $(64 \pm 6.5)$ & \\
\hline \multicolumn{3}{|l|}{ Sex } \\
\hline \multicolumn{2}{|c|}{ Male (54 - 78 years) } & $41(87 \%)$ \\
\hline \multicolumn{2}{|c|}{ Female (62 - 68 years) } & $6(13 \%)$ \\
\hline \multicolumn{3}{|c|}{ Smoking } \\
\hline & Current & $26(55 \%)$ \\
\hline & Ex. Smoker & $15(32 \%)$ \\
\hline & Never & $6(13 \%)$ \\
\hline \multicolumn{3}{|c|}{ Symptoms } \\
\hline & Cough & $39(83 \%)$ \\
\hline \multicolumn{2}{|r|}{ Wheeze } & $44(93.6 \%)$ \\
\hline \multicolumn{2}{|c|}{ Dyspnoea } & $28(59.6 \%)$ \\
\hline \multicolumn{2}{|c|}{ Tightness of Chest } & $24(51.06 \%)$ \\
\hline \multicolumn{2}{|c|}{$\begin{array}{l}\text { Nocturnal Symptoms } \\
\text { Table 4 Patient Chara }\end{array}$} & $21(44.7 \%)$ \\
\hline \multicolumn{3}{|c|}{ Table 4. Patient Characteristics in COPD } \\
\hline
\end{tabular}

In COPD, average age of patients is $64 \pm 6.5$. Males are 41 $(87 \%)$ and females are $6(13 \%)$. Symptoms are Cough 39 
(83\%), Wheeze 44 (93.6\%), Dyspnoea 28 (59.6\%), Tightness of chest $24(51.06 \%)$ and Nocturnal symptoms 2 (44.7\%).

\begin{tabular}{|c|c|}
\hline MMRC Grade of Dyspnoea & $\begin{array}{c}\text { Average } \text { FEV }_{\mathbf{1}} \text { Volume in } \\
\text { Litre }\end{array}$ \\
\hline 0 & No patients in this category \\
\hline I & 1.25 \\
\hline II & 1.21 \\
\hline III & 1.03 \\
\hline IV & 0.96 \\
\hline
\end{tabular}

Table 5. Grading of COPD Patients depending on MMRC Grade and Average FEV 1

Average FEV1 volume in litre in MMRC grade of dyspnoea 0 , I, II, III are 2.24, 2.12, 1.86, 1.74 respectively. No patients in MMRC grade of dyspnoea IV category.

In COPD patients, major symptoms are wheeze 44 (93.6\%) and cough 39 (83\%).

\begin{tabular}{|c|c|c|c|}
\hline $\begin{array}{c}\text { Age } \\
\text { (Years) }\end{array}$ & \multicolumn{3}{|c|}{ Clinical Outcome } \\
\hline & $\begin{array}{c}\text { Mean Duration } \\
\text { of Stay (Days) }\end{array}$ & Deaths & $\begin{array}{c}\text { Discharge with } \\
\text { Home Oxygen Therapy }\end{array}$ \\
\hline $31-40$ & 6 & - & \\
\hline $41-50$ & 7 & - & 3 \\
\hline $51-60$ & 12 & - & 3 \\
\hline $61-70$ & 10 & - & - \\
\hline $71-80$ & 15 & \multicolumn{4}{|c|}{ Table 6. Relation between Age } \\
\hline \multicolumn{4}{|c|}{ and Duration of Stay in Hospital } \\
\hline
\end{tabular}

Mean duration of stay is higher (15 days) in 71 - 80 years' age group compared to others.

\begin{tabular}{|c|c|c|c|c|c|c|}
\hline Variable & Diagnosis & $\mathbf{N}$ & Mean & \begin{tabular}{|c|} 
Std. \\
Deviation
\end{tabular} & $\begin{array}{c}\text { Independent } \\
\text { 't' test }\end{array}$ & $P$ value \\
\hline \multirow[b]{2}{*}{$\begin{array}{c}\text { FEV1 } \\
\text { PRE }\end{array}$} & COPD & 47 & 1.1368 & .48055 & -6.06 & \multirow[b]{2}{*}{$\begin{array}{c}0.00 \\
(\mathrm{p}<0.05)\end{array}$} \\
\hline & \begin{tabular}{|c|} 
Bronchial \\
Asthma
\end{tabular} & 47 & 1.9657 & .81502 & & \\
\hline \multirow[b]{2}{*}{$\begin{array}{l}\text { FEV1 } \\
\text { POST }\end{array}$} & COPD & 47 & 1.2353 & .49478 & -9.053 & \multirow[b]{2}{*}{$\begin{array}{c}0.00 \\
(\mathrm{p}<0.05)\end{array}$} \\
\hline & \begin{tabular}{|c|} 
Bronchial \\
Asthma
\end{tabular} & 47 & 2.5413 & .85632 & & \\
\hline \multirow{2}{*}{$\begin{array}{l}\text { Total } \\
\text { Score }\end{array}$} & COPD & 47 & 3.362 & 1.0514 & 2.143 & \multirow{2}{*}{$\begin{array}{c}0.035 \\
(p<0.05)\end{array}$} \\
\hline & \begin{tabular}{|l|} 
Bronchial \\
Asthma
\end{tabular} & 47 & 2.809 & 1.4240 & & \\
\hline $\begin{array}{l}T \\
B\end{array}$ & le 7. Asso & & ש שוח & हח & ind Total & $\begin{array}{l}\text { sof } \\
\text { ore }\end{array}$ \\
\hline
\end{tabular}

An independent sample ' $\mathrm{t}$ ' test revealed that there is statistically significant difference between COPD and Bronchial Asthma for FEV1 Pre, FEV1 Post and Total Score, ( $p$ $<0.05)$.

\section{DISCUSSION}

The study population included 47 Bronchial asthma and 47 COPD patients. In Bronchial asthma group, 27 were male and 20 were female with mean age of $33.3 \pm 14.1$. This study is comparable to John Eugene et al whose mean age group is $32.7+12.9$ and Fabio Savatore et al whose study group have mean age of $40.1+12.6$ among male patients, $42+12.3$ among female patients, and Liam Goh et al(5) whose study group aged between $14-84$ years with mean age of $51.1+16$.
In present study of Bronchial asthma group, male-tofemale ratio is 1:0.74. This is comparable to John Eugene et al,(6) whose study group have male-to-female ratio of 1:0.65 and Sherman Speizer et al(7) whose study group have maleto-female ratio of 1:1.24 and Fabio Savatore ${ }^{(8)}$ et al whose study group has male-to-female ratio of 1:1.5 and Liam Goh et al(5) whose male-to-female ratio is $1: 0.73$. Nevertheless, the prevalence of COPD reported in these studies varied from 2 $22 \%$ in men and from $1.2-19 \%$ in women. $\left.{ }^{9}\right)$

\begin{tabular}{|c|c|c|}
\hline Study & Year & Mean Age (Years) \\
\hline John Eugene et al ${ }^{(6)}$ & 1998 & $32.7+12.9$ \\
\hline${\text { Fabio Savatore et } \mathrm{al}^{(8)}}^{(8)}$ & 2002 & $41.1+12.5$ \\
\hline Liam Goh et al $(5)$ & 2001 & $51.1+16$ \\
\hline Present Study & 2016 & $33.3 \pm 14.1$ \\
\hline \multicolumn{2}{|c|}{ Table 8. Comparison of Mean Age } \\
in Bronchial Asthma in Various Studies \\
\hline
\end{tabular}

\begin{tabular}{|c|c|c|}
\hline Study & Year & $\begin{array}{l}\text { Male-to-Female } \\
\text { Ratio }\end{array}$ \\
\hline John, Eugene et al & 1998 & $1: 0.65$ \\
\hline $\begin{array}{l}\text { Sherman, Speizer et } \\
\text { al }\end{array}$ & 1992 & $1: 1.24$ \\
\hline Fabio Savatore et al & 2002 & $1: 1.5$ \\
\hline Liam, Goh et al & 2001 & $1: 0.73$ \\
\hline Present Study & 2016 & $1: 0.74$ \\
\hline \multicolumn{3}{|c|}{$\begin{array}{c}\text { Table 9. Comparison of Male-to-Female } \\
\text { Ratio in Bronchial Asthma in Various Studies }\end{array}$} \\
\hline
\end{tabular}

Age- In COPD group 41 were males and 6 females, aged between 54 and 78. This study is comparable to David Robert et al(10) whose age group is 17 years and older and Sherrill and Khudson et al whose age group is $>55 \mathrm{yrs}$.

\section{Not Comparable}

The symptom score in our study- five symptoms like cough, dyspnoea, wheeze, tightness of chest and nocturnal symptoms were recorded on a two-point scale. Zero point was given for absence of symptom and one point for presence of symptom. A cumulative symptom score was calculated with a maximum score of five. This is comparable to John Eugene et al,(6) in which patients were asked to quantify each of six current asthma symptoms including cough, dyspnoea, chest tightness, wheezing, sputum production and nocturnal awakening on a 0 (none) to 4 (constant) whole integer scale. Total asthma scores ranged from 0 to 24 by utilising this scale. Further our study is comparable to Sherman and Speizer et al, whose subjects were categorised based on the presence or absence of self-reported respiratory symptoms (persistent wheeze, chronic cough, chronic phlegm or shortness of breath) at the initial visit. Our study is comparable to Liam Goh et al. The symptom variations are often triggered by factors such as allergen or irritant exposure, exercise, change in weather or viral respiratory infections.(11) In which situation patients were requested to(a) Grade their asthma symptoms by giving an arbitrary score of 0 to 6 ( 0 being least affected and 6 being most affected) on the various effects that asthma symptoms had in their daily lives for the 2 weeks prior to the clinic visit; (b) State the number of days with asthma attacks; and (c) State the number of nights they were awoken by asthma symptoms. 
The possible total symptom score of each patient could have been 0 to 52 .

The symptom score of COPD group in our study is comparable to Sherrill and Khudson et al,(12) in which subjects were classified at each survey as having chronic cough, exertional dyspnoea or wheeze.

Our study showed that asthmatics tend to more frequently over-estimate their level of airway obstruction and some also tend to underestimate it. This further emphasises the importance of using objective measures of lung function in the assessment of asthma patients. Subjective wheezing was the best predictor of airway obstruction in asthmatics. Though asthmatics have been shown to more frequently identify wheezing as a characteristic of their exertional breathing difficulty than patients with other forms of cardiorespiratory disease. Persistent wheezing has also been shown to be predictive of airway obstruction in population-based studies of wheezy and asthmatic individuals. Kelsen et al found that approximately 10 percent of patients who were believed to have clinical improvement in Bronchial asthma did not demonstrate any improvement in post-bronchodilator $\mathrm{FEV}_{1}$. Exacerbations and co-morbidities contribute to the overall severity in individual patients. According to the 12-site Burden of Obstructive Lung Disease (BOLD) study, the average prevalence of COPD is $10.1 \%$ with wide variations.(13) It is after publication of the results of INSEARCH II (Indian Study on Epidemiology of Asthma, Respiratory Symptoms and Chronic Bronchitis in Adults' (INSEARCH) phase II), some nationwide prevalence data are available. ${ }^{(14)}$

The GOLD guidelines are useful for classifying severity of COPD.(15) According to GINA 2015- asthma severity can be assessed when the patient has been on regular controller treatment for several months.(16)

The academic term- Exacerbation is commonly used in scientific and clinical literature, although hospital-based studies more often refer to acute severe asthma. However, the term exacerbation is not suitable for use in clinical practice, as it is difficult for many patients to pronounce and remember. (17)

Thus, GOLD recommends active case finding,(18) but not screening spirometry.

In our study in asthma group, potentially 43\% (under estimators + over estimators) of patients initially evaluated would have been treated improperly if assessed solely on the basis of their symptoms. Under estimators had relatively asymptomatic airway obstruction. However, this subgroup of patients should be treated with a level of therapy commensurated with their degree of airway obstruction for the following reasons. Treatment(19)_ A step-wise management of inhalational corticosteroid was added to reliever step wise.

The airway obstruction that occurs in asthma is thought to be a manifestation of airway inflammation and airway wall remodelling leading to fixed airway obstruction as a potential complication of chronic airway inflammation, which can be seen even in patients with clinically mild disease. Also, a number of other well-known asymptomatic conditions such as hypertension, hypercholesterolaemia and hyperglycaemia are known to result in irreversible end-organ damage if left untreated. McFaden et al(20) found that signs of airway obstruction remit following acute bronchodilator administration, even though $\mathrm{FEV}_{1}$ remains around 50 percent of predicted value, while clinical symptoms disappear with an $\mathrm{FEV}_{1}$ of around 63 percent of predicted normal.

JC Bestall et al(21) demonstrated that MRC dyspnoea grading scale is a simple and valid method of categorising patients with COPD. FEV 1 was lowest with the highest MRC grade, though it was not statistically significant. This finding was similar in our study.

\section{CONCLUSION}

- In present study, total patients are 94; 47 patients are Asthmatics and 47 patients have COPD.

- In asthma patients, age ranges between 18 to 71 years.

- Out of 47 asthma patients, $57 \%$ are males and $43 \%$ are females.

- In asthma patients, major symptoms are chest tightness $28(59.6 \%)$ followed by cough $27(57.5 \%)$ and wheeze $27(57.5 \%)$.

- In asthmatics average, FEV1 value (pre-bronchodilator) average was $1.97+/-0.82$ and post-bronchodilator FEV1 value (post-bronchodilator) average was $2.54+$ +/- 0.86 .

- In COPD patients, age is between 54 to 78 years.

- In COPD patients, males are $87 \%$ and females are $13 \%$.

- In COPD patients, smokers are 55\% and non-smokers are $45 \%$.

- Wheeze 44 (93.6\%) and Dyspnoea 28 (59.6\%) are main symptoms in COPD.

- In COPD, average FEV1 is (pre-bronchodilator) 1.15 +/0.47 and post-bronchodilator FEV1 is $1.24+/-0.47$.

- In the current study, there is statistically significant difference between COPD and Bronchial Asthma for FEV1 Pre, FEV1 Post and Total Score, $(\mathrm{p}<0.05)$.

\section{REFERENCES}

[1] Global Initiative for Chronic Obstructive Lung Disease (GOLD). Global strategy for the diagnosis, management and prevention of COPD 2015. Chapter 1, Definition and overview 2015:1-7.

[2] Emerman CL, Lukens TW, Effron D. Physician estimation of $\mathrm{FEV}_{1}$ in acute exacerbation of COPD. Chest 1994;105(6):1709-12.

[3] Ciba Guest Symposium Report. Terminology, definitions and classification of chronic pulmonary emphysema and related conditions. Thorax 1959;14(4):286-99.

[4] Standards for the diagnosis and care of patients with chronic obstructive pulmonary disease (COPD) and asthma. This official statement of the American thoracic society was adopted by the ATS board of directors, November 1986. Am Rev Respir Dis 1987;136(1):225-44.

[5] Liam CK, Goh CT, Isahak M, et al. Relationship between symptoms and objective measures of airway obstruction in asthmatic patients. Asian Pac J allergy Immunol 2001;19(2):79-83.

[6] Teeter JG, Bleecker ER. Relationship between airway obstruction and respiratory symptoms in adult asthmatics. Chest 1998;113(2):272-7.

[7] Sherman CB, Xu X, Speizer FE, et al. Longitudinal lung function decline in subjects with respiratory symptoms. Am Rev Respir Dis 1992;146(4):855-9. 
[8] Cibella F, Bucchiert S, Bonsignore G. Lung function decline in Bronchial asthma. Chest 2002;122(6):19448.

[9] Salvi S. COPD: the neglected epidemic. In: Jindal SK, (edr). Textbook of pulmonary and critical care med. $1^{\text {st }}$ edn. Jaypee Publications: New Delhi 2011:971-4.

[10] Mannino DM, Gagnon RC, Petty TL, et al. Obstructive lung disease and low lung function in adults in the United States: data from the national health and nutrition examination survey, 1988-1994. Arch Intern Med 2000;160(11):1683-9.

[11] Global Initiative for Asthma (GINA). Global strategy for asthma management and prevention 2015. Chapter 1, definition, description and diagnosis of asthma 2015:1-11.

[12] Sherrill DL, Lebowitz MD, Knudson RJ, et al. Longitudinal methods for describing the relationship between pulmonary function, respiratory symptoms and smoking in elderly subjects: the tuscon study. Eur Respir J 1993;6(3):342-8.

[13] Gupta D, Agarwal R, Aggarwal AN, et al. Guidelines for diagnosis and management of chronic obstructive pulmonary disease: joint ICS/NCCP (I) recommendations. Lung India 2013;30(3):228-67.

[14] McKay AJ, Mahesh PA, Fordham JZ, et al. Prevalence of COPD in India: a systematic review. Prim Care Respir J 2012;21(3):313-21.
[15] Global Initiative for Chronic Obstructive Lung Disease (GOLD). Global strategy for the diagnosis, management and prevention of COPD 2015. Chapter 2, Diagnosis and assessment 2015:8-18.

[16] Global Initiative for Asthma (GINA). Global strategy for asthma management and prevention 2015. Chapter 2, Assessment of asthma 2015:13-22.

[17] Global Initiative for Asthma (GINA). Global strategy for asthma management and prevention 2015. Chapter 4 Management of worsening asthma and exacerbations 2015:57-72.

[18] Dirven JA, Tange HJ, Muris JW, et al. Early detection of COPD in general practice: implementation, workload and socioeconomic status. A mixed methods observational study. Prim Care Respir J 2013;22(3):338-43.

[19] Global Initiative for Asthma (GINA). Global strategy for asthma management and prevention 2015. Chapter 3, Treatment of asthma to control symptoms and minimize risk 2015:23-55.

[20] McFadden ER, Kiser R, DeGroot WJ. Acute bronchial asthma. Relations between clinical and physiologic manifestations. N Engl J Med 1973;288(5):221-5.

[21] Bestall J, Paul E, Garrod R, et al. Usefulness of the medical research council (MRC) dyspnoea scale as a measure of disability in patients with chronic obstructive pulmonary disease. Thorax 1999;54(7):581-6. 